\title{
Phase Transformations in Thermally Treated Gas-Atomized Al 7075 Powder
}

\author{
Caitlin Walde $^{1} \cdot$ Kyle Tsaknopoulos $^{1} \cdot$ Victor Champagne $^{2} \cdot$ Danielle Cote $^{1}$
}

Received: 15 April 2019 / Revised: 9 March 2020 / Accepted: 2 April 2020 / Published online: 23 April 2020

(c) The Author(s) 2020

\begin{abstract}
Al 7075 is a heat-treatable $\mathrm{Al}-\mathrm{Mg}-\mathrm{Zn}$ alloy widely used in the aerospace industry. Recently, it has found application as feedstock for metal additive manufacturing (MAM). It has been shown that wrought alloy compositions in powder form differ in microstructure and properties from their conventional form. Given this, it is important to understand the microstructure of the powders prior to use in MAM processes. This work studies as-atomized gas-atomized Al 7075 powders and the effect of thermal treatments on microstructure. Extensive electron microscopy revealed the presence of T-phase, $\mathrm{Al}_{7} \mathrm{Cu}_{2} \mathrm{Fe}$, and $\mathrm{Mg}_{2} \mathrm{Si}$ in the as-atomized condition. Thermal treatments were performed at $465^{\circ} \mathrm{C}$ and $480{ }^{\circ} \mathrm{C}$ to homogenize the microstructure; however, S-phase was unexpectedly present in the samples treated at $465^{\circ} \mathrm{C}$. In both $465{ }^{\circ} \mathrm{C}$ and $480{ }^{\circ} \mathrm{C}$ treatments, T-phase was not fully dissolved after the 60 -min treatment. Guided by thermodynamic modeling, these results indicate a shift in local equilibria in these powders.
\end{abstract}

Keywords Powder metallurgy $\cdot$ Modeling $\cdot$ Microstructure $\cdot$ Aluminum alloys

\section{Introduction}

$\mathrm{Al} 7075$ is a heat-treatable $\mathrm{Al}-\mathrm{Mg}-\mathrm{Zn}$ alloy that is widely used in the aerospace industry in compressively loaded parts for its combination of high specific strength and resistance to stress corrosion cracking [1]. Al 7075 is available in multiple forms; it is typically cast and then worked to a wrought condition, though it is also available in wires and powders. The latter forms are used mainly as feedstock in metal additive manufacturing (MAM) processes. Powder-bed processes are more common, with selective laser melting (SLM), powder bed fusion (PBF), and selective laser sintering (SLS) having perhaps the most widespread use [2]. In liquid-state processes, where the powder is melted during consolidation, features present in the feedstock powder-such as surface oxides and internal porosity — can be retained during consolidation, while the rest of the features are melted and reform. In solid-state processes, where the powder is not

Danielle Cote

dlcote2@wpi.edu

1 Worcester Polytechnic Institute, Worcester, MA, USA

2 US Army Research Laboratory, Aberdeen Proving Grounds, Aberdeen, MD, USA melted during consolidation, the retention of feedstock characteristics is more significant. Features such as secondary phases, in addition to surface oxides and internal porosity, can be retained during consolidation. For example, Rokni et al. [3] showed that the feedstock powder microstructure is retained in cold spray deposits. With this in mind, it is important to understand the microstructure of the powders prior to consolidation $[4,5]$.

The feedstock powders are often gas-atomized, experiencing cooling rates on the order of $10^{6}{ }^{\circ} \mathrm{C} / \mathrm{s}$ during solidification [6]. This categorizes the powders as rapidly solidified, which results in microstructures very different than conventional castings, where the cooling rate is on the order of less than $10^{2}{ }^{\circ} \mathrm{C} / \mathrm{s}$ [5]. Minimal segregation, nonequilibrium phases, and microstructure homogeneity are characteristics of rapidly solidified structures [6-8].

The three primary steps in a heat treatment are solutionization, quenching, and aging [9]. The purpose of the solutionizing step is to dissolve secondary phases and achieve a homogenous microstructure; this is typically performed at elevated temperatures in the $450-550{ }^{\circ} \mathrm{C}$ range, depending on the alloy. This step is followed by a rapid quench, to maintain the supersaturated metastable microstructure at room temperature. The aging step is designed to homogenously nucleate and grow the primary strengthening phase 
in the alloy; this is usually performed at lower temperatures in the $150-250{ }^{\circ} \mathrm{C}$ range, depending on the alloy. For $\mathrm{Al} 7075$, the strengthening sequence is GP zones $(\mathrm{MgZn}) \rightarrow \eta^{\prime} \rightarrow \eta\left(\mathrm{MgZn}_{2}\right) \rightarrow \mathrm{T}^{\prime} \rightarrow \mathrm{T} \rightarrow\left(\mathrm{Al}_{2} \mathrm{Mg}_{3} \mathrm{Zn}_{3}\right)$ [9]. Whether the sequence finishes at $\eta$ - or at $\mathrm{T}$-phase depends on the $\mathrm{Mg} / \mathrm{Zn}$ ratio. Natural aging typically continues for years, so artificial aging steps are important to achieve stable precipitates. Additionally, as $\mathrm{Fe}$ and $\mathrm{Si}$ are impurities in $\mathrm{Al}, \mathrm{Al}_{7} \mathrm{Cu}_{2} \mathrm{Fe}, \mathrm{Al}_{12}(\mathrm{Fe}, \mathrm{Mn})_{3} \mathrm{Si}, \mathrm{Al}_{6}(\mathrm{Fe}, \mathrm{Mn}), \mathrm{Mg}_{2} \mathrm{Si}$, $\mathrm{SiO}_{2}$, and $\mathrm{Al}_{23} \mathrm{CuFe}_{4}$ are also common phases in $\mathrm{Al} 7075$, in addition to the $\eta$ and $\mathrm{T}$ strengthening phases. Depending on the exact alloy compositions, some of these phases may be insoluble. Of note is that $\mathrm{Mg}_{2} \mathrm{Si}$ is virtually insoluble in $\mathrm{Al} 7075$ [1].

Because features in the powder are retained during consolidation, the as-atomized microstructure can be controlled using thermal treatments. Recent research has shown the retention of feedstock powder microstructure during consolidation for other alloys, though that research included a limited analysis of the internal microstructure of the powders, not fully investigating the effect of the thermal treatments on the powders [10-14]. These researchers assumed the network of solute elements at the boundaries in the as-atomized structure, as seen in scanning electron microscopy (SEM) and energy-dispersive $\mathrm{X}$-ray spectroscopy (EDS), was segregation. While the presence of secondary phases was noted in the thermally treated powders, no further in-depth analysis was performed to identify the phases. However, in-depth analysis here indicates the as-atomized microstructure of the powders is actually distinct phases, as revealed using transmission electron microscopy (TEM), consistent with what is expected in rapid solidification $[4,15]$. Additionally, it was recently noted that these gas-atomized powders have both granular and subgranular features. The secondary phases exist at all boundaries, with groups of subgrains having the same orientation, comprising larger grains [4, 5, 15]. The size of the substructure is typically what is reported for these powders; when etched, it is impossible to distinguish between the high-angle and low-angle boundaries that differentiate the grains and subgrains.

Solutionization times for Al 7075 are typically on the order of 4-16 h for wrought components, depending on part size [9]. Given this timescale, other researchers chose to use long heat treatment times for their powders; however, other researches performed on Al 6061 indicated faster diffusion times in powders, resulting in the need for shorter thermal treatments $[5,10]$.

This research investigates the effect of thermal treatment on the transformations of the secondary phases present in gas-atomized $\mathrm{Al} 7075$ powders through the use of TEM and EDS.
Table 1 Powder composition compared to ASTM standard

\begin{tabular}{lcl}
\hline Element & Wt.\% & ASTM B209 \\
\hline $\mathrm{Cr}$ & 0.210 & $0.18-0.28$ \\
$\mathrm{Cu}$ & 1.700 & $1.2-2.0$ \\
$\mathrm{Fe}$ & 0.180 & 0.50 \\
$\mathrm{Mg}$ & 2.300 & $2.1-2.9$ \\
$\mathrm{Mn}$ & 0.031 & 0.30 \\
$\mathrm{Si}$ & 0.110 & 0.40 \\
$\mathrm{Ti}$ & 0.031 & 0.20 \\
$\mathrm{Zn}$ & 5.600 & $5.1-6.1$ \\
Other & & 0.15 \\
$\mathrm{Al}$ & 89.8 & Remainder \\
\hline
\end{tabular}

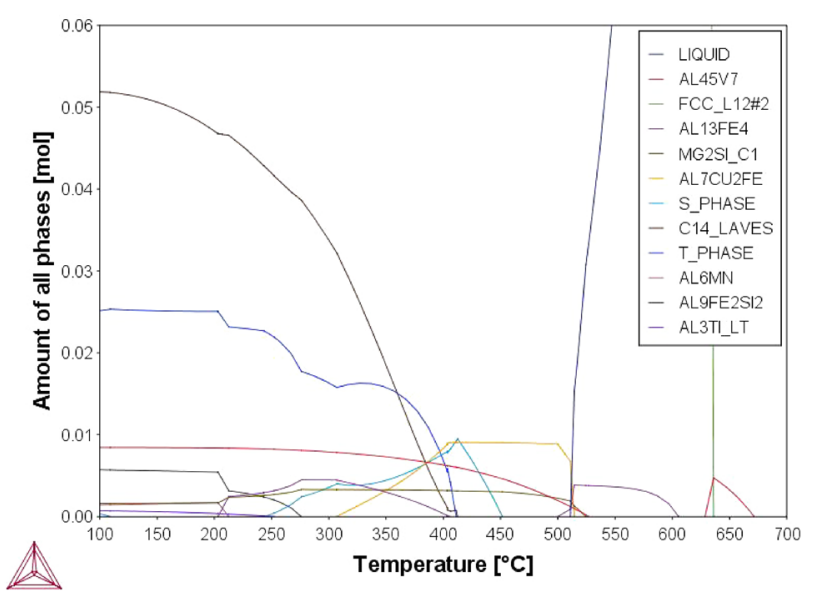

Fig. 1 Equilibrium diagram, as predicted by thermo-calc simulations. Amount of phases present as a function of temperature for the specific composition of the alloy investigated given in Table 1

\section{Method}

The studied powder was gas-atomized Al 7075 (Valimet, Inc., Stockton, CA) with a $d_{10}$ of $26.1 \mu \mathrm{m}, \mathrm{d}_{50}$ of $37.1 \mu \mathrm{m}$, and $\mathrm{d}_{90}$ of $52.5 \mu \mathrm{m}$. The composition of the powders, as determined by direct-current plasma emission spectroscopy and shown in Table 1, is within the acceptable ranges for $\mathrm{Al} 7075$ [16, 17].

Thermal treatment parameters were determined with the assistance of computational thermodynamic and kinetic software (Thermo-Calc, Stockholm, Sweden), shown in Fig. 1. Thermal treatments were performed with the goal of homogenizing the microstructure-dissolving T-phase while avoiding S-phase growth, avoiding $\mathrm{Al}_{7} \mathrm{Cu}_{2} \mathrm{Fe}$ coarsening, and avoiding melting. The temperature of $465{ }^{\circ} \mathrm{C}$ was selected to reduce the coarsening effect of $\mathrm{Al}_{7} \mathrm{Cu}_{2} \mathrm{Fe}$ by maintaining a lower temperature to slow diffusion while still avoiding the formation of S-phase, which is present below $450{ }^{\circ} \mathrm{C}$. The temperature of $480{ }^{\circ} \mathrm{C}$ was chosen 
because it is the conventional solutionization temperature used for $\mathrm{Al} \mathrm{7075.} \mathrm{Treatment} \mathrm{times} \mathrm{ranged} \mathrm{from} 0$ to $4 \mathrm{~h}$. The "as-atomized" indicates an untreated condition, while the thermally treated conditions are noted by the time at treatment temperature; the thermally treated samples all experienced the ramp to elevated temperature. Samples were treated in a nitrogen environment in a differential scanning calorimeter (DSC) because of its high thermal accuracy. One sample was left untreated, in the as-atomized condition.

Samples were prepared for scanning electron microscopy (SEM) and energy-dispersive X-ray spectroscopy (EDS) analyses by mounting the powders in a hot-cure epoxy and grinding and polishing incrementally with a final $0.25 \mu \mathrm{m}$ colloidal silica suspension.

SEM and EDS analyses were performed on all samples using a tungsten-filament SEM at 10-15 kV. Powders in both the as-atomized and thermally treated conditions of $465^{\circ} \mathrm{C}$ for $60 \mathrm{~min}$ and $480{ }^{\circ} \mathrm{C}$ for $60 \mathrm{~min}$ were prepared for transmission electron microscopy (TEM) analysis using focused ion beam (FIB) milling (Scios DualBeam and Helios 660 Nanolab, Thermo Fisher Scientific, Waltham, MA) [15]. Lamellae were polished with a final beam current of $0.1 \mathrm{nA}$ and had a final thickness of less than $200 \mathrm{~nm}$. TEM analysis was performed using a probe-corrected TEM (Titan Themis with ChemiSTEM, Thermo Fisher Scientific, Waltham, MA) and energy-dispersive X-ray spectroscopy (EDS) (Super-X, Thermo Fisher Scientific, Waltham, MA) at an accelerating voltage of $300 \mathrm{kV}$. The amounts of secondary phases present in the conditions were quantified using image contrast thresholding. All EDS maps are in wt.\%.

Additionally, the as-atomized condition was evaluated using electron backscatter diffraction (EBSD). FIB was used to prepare powder particles for EBSD analysis, and an accelerating voltage of $20 \mathrm{kV}$ with a step size of $0.3 \mu \mathrm{m}$ was used for analysis.

\section{Results and Discussion}

Figure 2 displays an overview SEM micrograph and EBSD micrograph of the as-atomized condition. The continuous network structure present at both the granular and substructure boundaries, as seen in the SEM micrograph, in the asatomized condition is consistent with what is seen in other gas-atomized powders [15]. Note that when orientation is evaluated, as with EBSD in Fig. $2 b$, there are regions of the substructure that have the same orientation and comprise grains, again consistent with what is seen in similar powders $[4,5,15]$.

Figure 3 shows overview SEM micrographs of the thermally treated conditions. As seen in Fig. 3a and b, the network structure present in the as-atomized condition begins
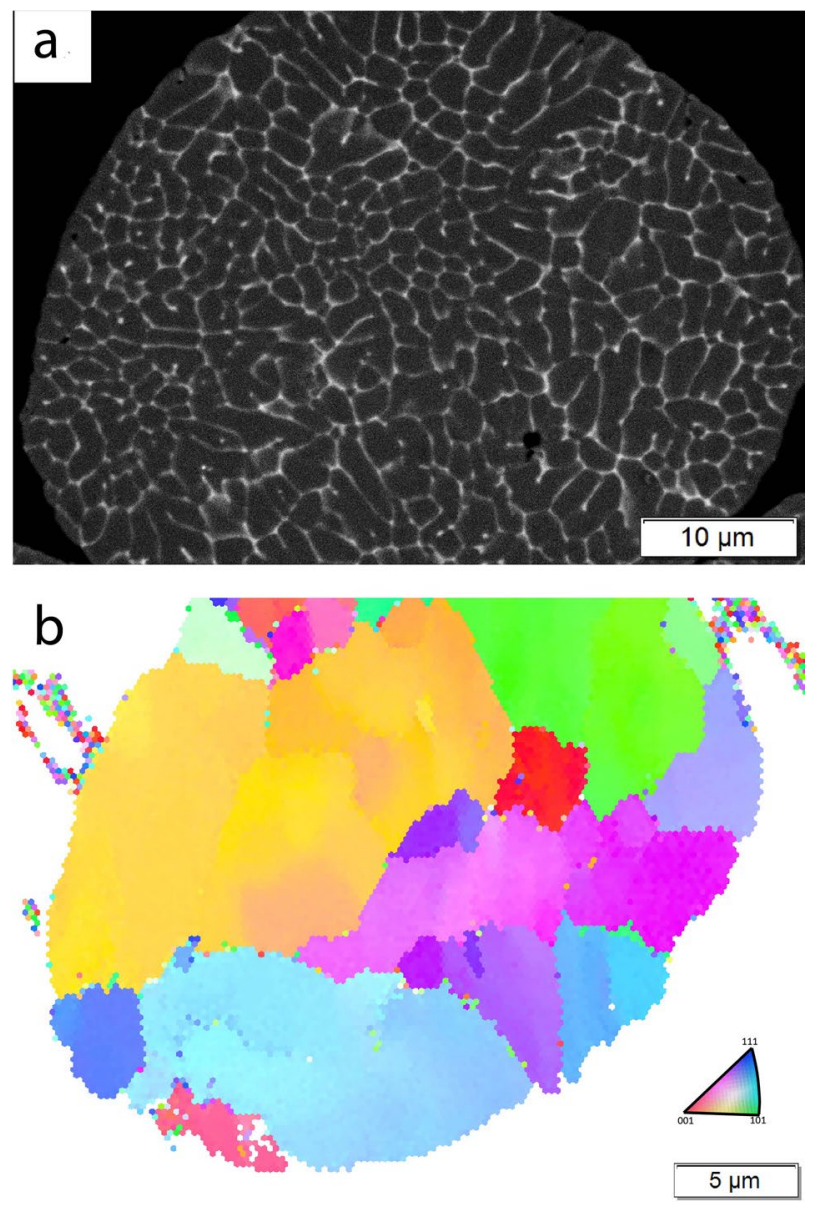

Fig. 2 Overview SEM micrograph and EBSD micrograph of the asatomized condition

to dissolve simply by bringing the powder up to an elevated temperature. With increased treatment times, note the presence of both larger phases and smaller phases in two different regions; the large phases are present at the grain boundaries, such as seen in Fig. 2b, while the smaller phases are present at only the substructure boundaries.

Figure 4 shows the area percent of secondary phases present as a function of treatment time for both treatment temperatures.

In the treatment performed at $465{ }^{\circ} \mathrm{C}$, there is an initial decrease in secondary phase amount after the sample reaches the set temperature, consistent with Fig. 3. Then, there is a slight decrease in amount of light-contrasting secondary phases after $20 \mathrm{~min}$ of treatment, stabilizing after 60 min of treatment. The dark-contrasting phases, while not detected in the as-atomized condition, are stable in very low amounts across all treatment temperatures.

In the treatment performed at $480{ }^{\circ} \mathrm{C}$, there is an initial decrease in secondary phases after increasing the sample to the set temperature, consistent with Fig. 3d, after which there is a slight increase in the light-contrasting phases 

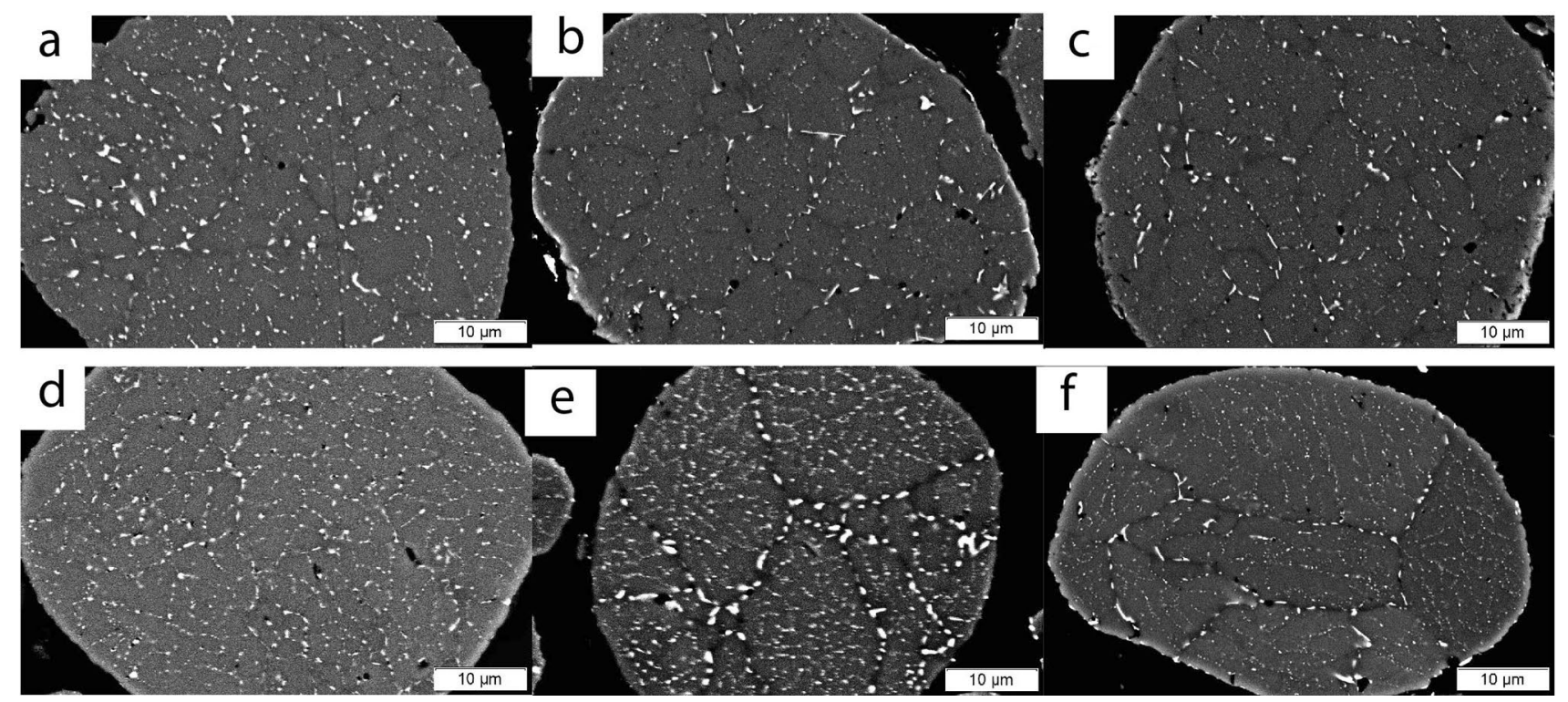

Fig. 3 Overview SEM micrographs of the thermally treated conditions. (a) $465{ }^{\circ} \mathrm{C}$ for 0 min, (b) $465{ }^{\circ} \mathrm{C}$ for $60 \mathrm{~min}$, (c) $465{ }^{\circ} \mathrm{C}$ for $120 \mathrm{~min}$, (d) $480{ }^{\circ} \mathrm{C}$ for $0 \mathrm{~min}$, (e) $480{ }^{\circ} \mathrm{C}$ for $60 \mathrm{~min}$, (f) $480{ }^{\circ} \mathrm{C}$ for $120 \mathrm{~min}$

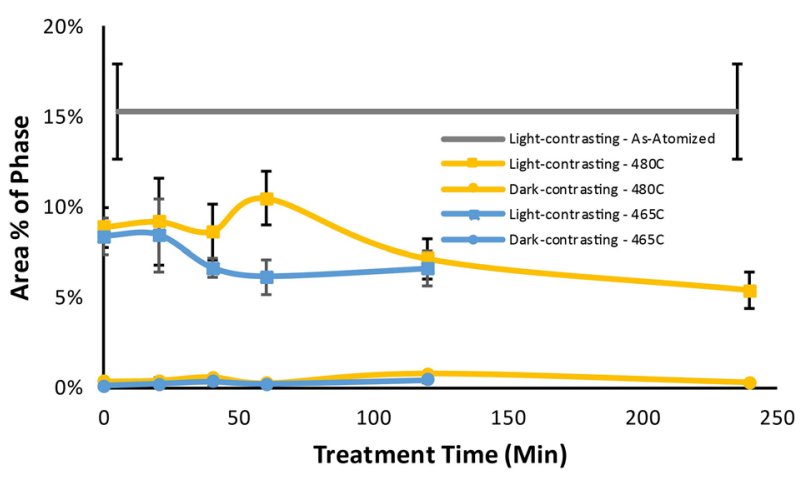

Fig. 4 Area percent of secondary phases present as a function of treatment time for both the treatment temperatures

until $60 \mathrm{~min}$ of treatment. After $60 \mathrm{~min}$, the light-contrasting phases decrease. The dark-contrasting phase, while not detected in the as-atomized condition, is stable across all treatment temperatures.

When comparing the two treatment temperatures, it is of note that the dark-contrasting phase area percent is the same, whereas the light-contrasting phase trends vary. There is a similar reduction in the light-contrasting phase in both treatments when at the set temperature. However, after approximately 20 min of treatment, the trends diverge; at $480{ }^{\circ} \mathrm{C}$, the light-contrasting phase increases, while at $465{ }^{\circ} \mathrm{C}$ the light-contrasting phase decreases. After approximately 120 min of treatment, the trends converge again, appearing to reach an equilibrium.

Due to the large interaction volume in the SEM, EDS was not successful in further differentiating the light- and dark-contrasting phases into the constituents predicted in Thermo-Calc. Hence, TEM evaluation was performed. Diffraction was attempted, but due to the small size of the phases and overlap in diffraction patterns of the phases, $\mathrm{Al}$ matrix was unsuccessful in confirming the phases. EDS was performed in a TEM to better understand which phases may be forming.

Figure 5 shows overview TEM micrographs of the asatomized and thermally treated conditions for $60 \mathrm{~min}$ at each temperature. Figure 5a shows a similar structure as seen in the SEM in Fig. 2a; on the other hand, Fig. 5b and c provides much more detail than their SEM counterparts in Fig. 3. Figures 6, 7 and 8 show higher magnification TEM micrographs and corresponding EDS maps to give further insight into the specific constituents present in each condition.

Figure 6 shows TEM micrograph and EDS maps for the as-atomized condition. Note the presence of two phases-an $\mathrm{Al}-\mathrm{Cu}-\mathrm{Mg}-\mathrm{Zn}$ network phase and discrete Fe-rich phases. EDS point quantification results are shown in Table 2, while the predicted compositions are shown in Table 3. Figure 1 is consulted to evaluate which phases may be present, and then, Tables 2 and 3 are compared, looking for overlaps in proportions of elements present. For example, the network phase at the boundaries in the as-atomized condition is rich in $\mathrm{Al}-\mathrm{Cu}-\mathrm{Mg}-\mathrm{Zn}$, and $\mathrm{T}$-phase and $\mathrm{V}$-phase are the only phases that fit the composition for that but T-phase is the only phase predicted at equilibrium (Fig. 1). Additionally, discrete $\mathrm{Fe}$-rich phases present at the boundaries are also rich with $\mathrm{Al}$ and $\mathrm{Cu}$. Consulting Table 3, it can be seen that $\mathrm{Al}_{7} \mathrm{Cu}_{2} \mathrm{Fe}$ is the only phase rich in just $\mathrm{Al}, \mathrm{Fe}$, and $\mathrm{Cu}$. This indicates the $\mathrm{Al}-\mathrm{Cu}-\mathrm{Mg}-\mathrm{Zn}$ network is likely T-phase and 


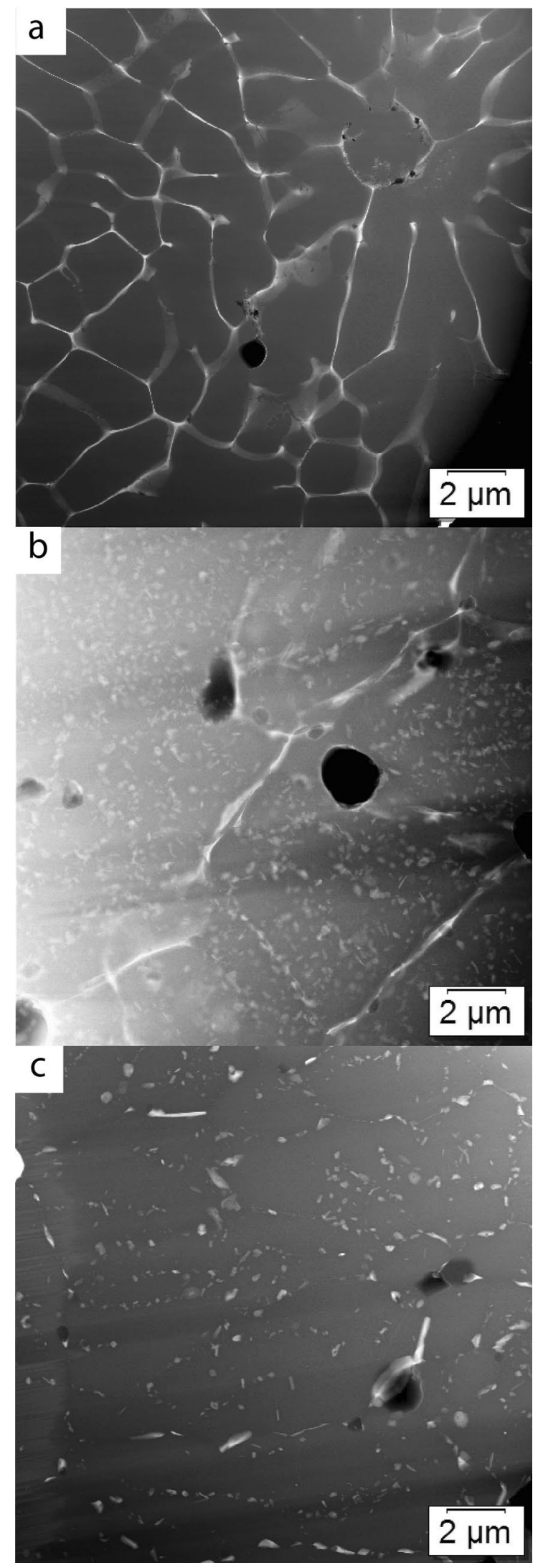

Fig. 5 Overview TEM micrographs of (a) the as-atomized condition, (b) 60 min at $465^{\circ} \mathrm{C}$ and (c) $60 \mathrm{~min}$ at $480{ }^{\circ} \mathrm{C}$ the discrete Fe-rich phases are likely $\mathrm{Al}_{7} \mathrm{Cu}_{2} \mathrm{Fe}$, which is consistent with what is seen in literature [1]. Additionally, the dark-contrasting phase seen in the thermally treated SEM micrographs (Figs. 3 and 4) is also found in the as-atomized structure using TEM and has been identified as $\mathrm{Mg}_{2} \mathrm{Si}$ through similar comparison of Tables 2 and 3.

Figure 7 shows TEM micrograph and EDS maps for the sample thermally treated at $465{ }^{\circ} \mathrm{C}$ for $60 \mathrm{~min}$. Note the presence of four phases-an $\mathrm{Al}-\mathrm{Cu}-\mathrm{Mg}-\mathrm{Zn}$ phase, an $\mathrm{Al}-\mathrm{Cu}-\mathrm{Mg}$ phase, an Fe-rich phase, and a Si-rich phase. EDS point quantification results are shown in Table 2 . The compositions of the predicted secondary phases, shown in Table 3, compared to the results in Table 2, indicate the Al-Cu-Mg-Zn phase to likely be residual T-phase that had not fully dissolved, the $\mathrm{Al}-\mathrm{Cu}-\mathrm{Mg}$ phase to be S-phase, the Fe-rich phase to be the $\mathrm{Al}_{7} \mathrm{Cu}_{2} \mathrm{Fe}$, and the $\mathrm{Si}$-rich phase to be $\mathrm{Mg}_{2} \mathrm{Si}$. Based on the equilibrium diagram in Fig. 1, $\mathrm{S}$-phase is not expected to be present at this temperature; this indicates a difference in the local equilibrium for the powder in comparison with the global powder composition as measured by direct-current plasma emission spectroscopy.

Figure 8 shows a TEM micrograph and EDS maps for the sample thermally treated at $480{ }^{\circ} \mathrm{C}$ for $60 \mathrm{~min}$. Note the presence of three phases - an $\mathrm{Al}-\mathrm{Cu}-\mathrm{Mg}-\mathrm{Zn}$ phase, an Fe-rich phase, and a Si-rich phase. EDS point quantification is shown in Table 2. The compositions of the predicted secondary phases, shown in Table 3 , compared to the results in Table 2, indicate the $\mathrm{Al}-\mathrm{Cu}-\mathrm{Mg}-\mathrm{Zn}$ phase to likely be residual $\mathrm{T}$-phase that had not fully dissolved, the Fe-rich phase to be the $\mathrm{Al}_{7} \mathrm{Cu}_{2} \mathrm{Fe}$, and the $\mathrm{Si}$-rich phase to be $\mathrm{Mg}_{2} \mathrm{Si}$. Note the lack of the S-phase that was present in the $465{ }^{\circ} \mathrm{C}$ thermally treated condition.

An unexpected similarity between the treatment temperatures is the presence of $\mathrm{T}$ phase seen in Figs. 7 and 8. The equilibrium predictions indicate that T-phase should not be present at either temperature; this indicates that $60 \mathrm{~min}$ of treatment at either temperature is not the sufficient time to dissolve the T-phase. As Scheil simulations predict T-phase to be the most abundant phase, it is expected that it may take additional time to dissolve. Unfortunately, it is not possible to distinguish between the $\mathrm{T}$-phase and $\mathrm{Al}_{7} \mathrm{Cu}_{2} \mathrm{Fe}$ in the SEM (Fig. 3), so further TEM work would be needed to determine whether $120 \mathrm{~min}$ or $240 \mathrm{~min}$ of treatment is sufficient to fully dissolve T-phase.

Additionally, large and small phases can be seen in both the SEM and TEM micrographs; they have been identified as both $\mathrm{T}$-phase and $\mathrm{Al}_{7} \mathrm{Cu}_{2} \mathrm{Fe}$, with sizes corresponding to different boundary types. The high-angle boundaries have more open space and hence the phases can be larger there, whereas the phases at the low-angle boundaries have less open space for growth.

Of significant note is the difference in precipitate locations between the $465^{\circ} \mathrm{C}$ and $480{ }^{\circ} \mathrm{C}$ treatment temperatures; 


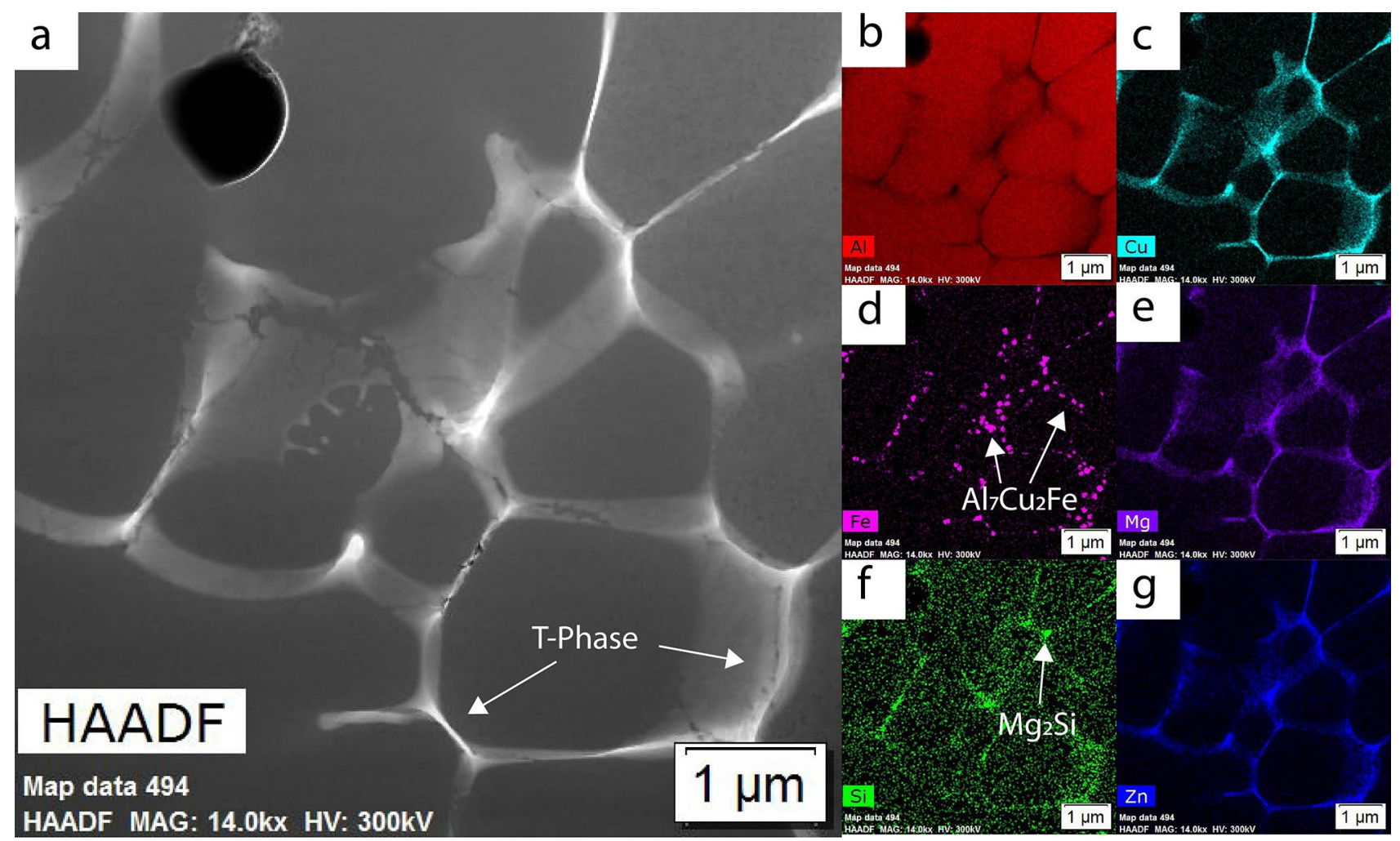

Fig. 6 TEM micrograph and EDS maps for the as-atomized condition. (a) HAADF, (b) $\mathrm{Al},(\mathbf{c}) \mathrm{Cu},(\mathbf{d}) \mathrm{Fe},(\mathbf{e}) \mathrm{Mg}$, (f) $\mathrm{Si}$, and (g) $\mathrm{Zn}$

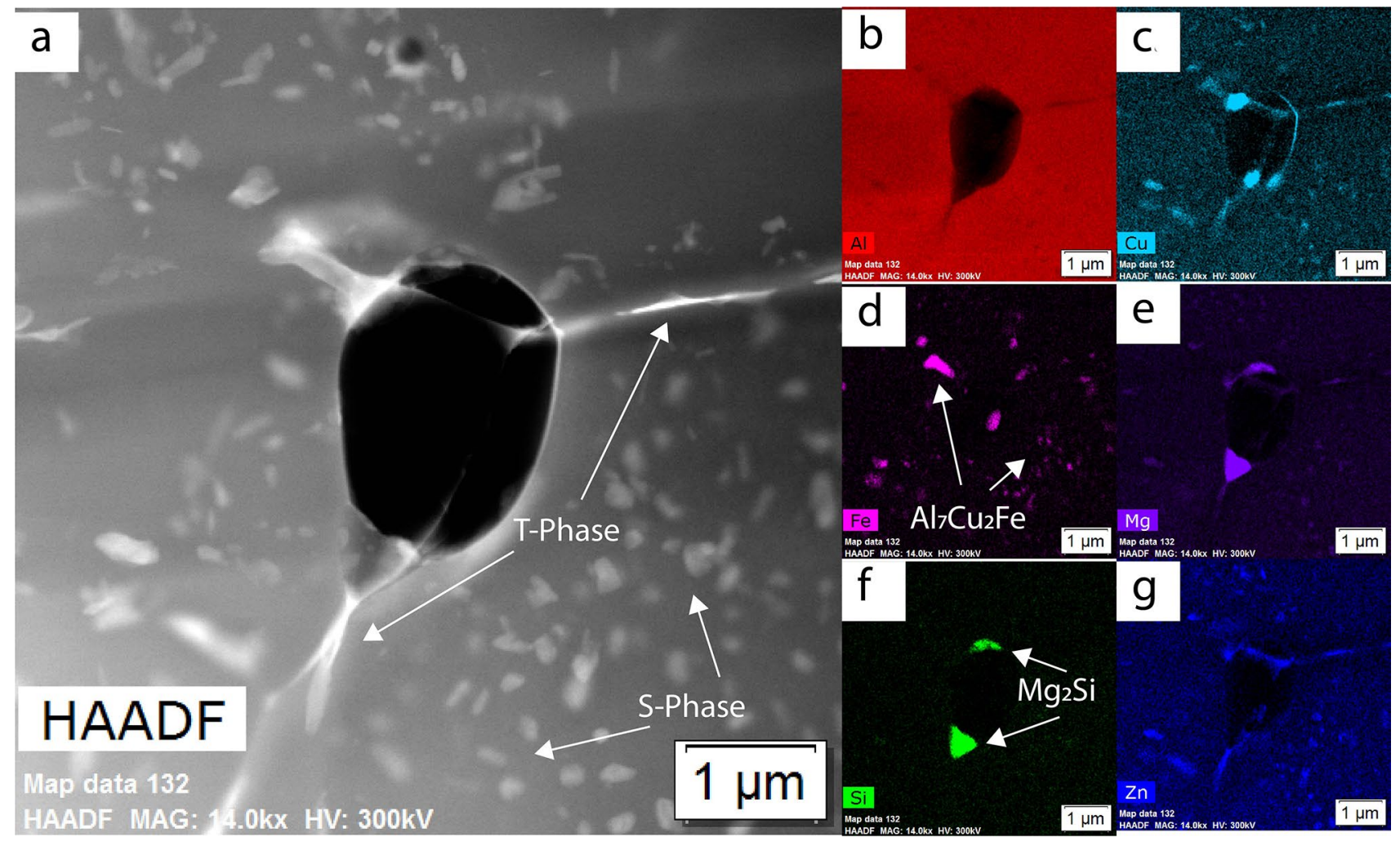

Fig. 7 TEM micrograph and EDS maps for the $60 \mathrm{~min}$ at $465^{\circ} \mathrm{C}$ condition. (a) $\mathrm{HAADF}$, (b) $\mathrm{Al},(\mathbf{c}) \mathrm{Cu},(\mathbf{d}) \mathrm{Fe},(\mathbf{e}) \mathrm{Mg}$, (f) $\mathrm{Si}$, and (g) $\mathrm{Zn}$ 


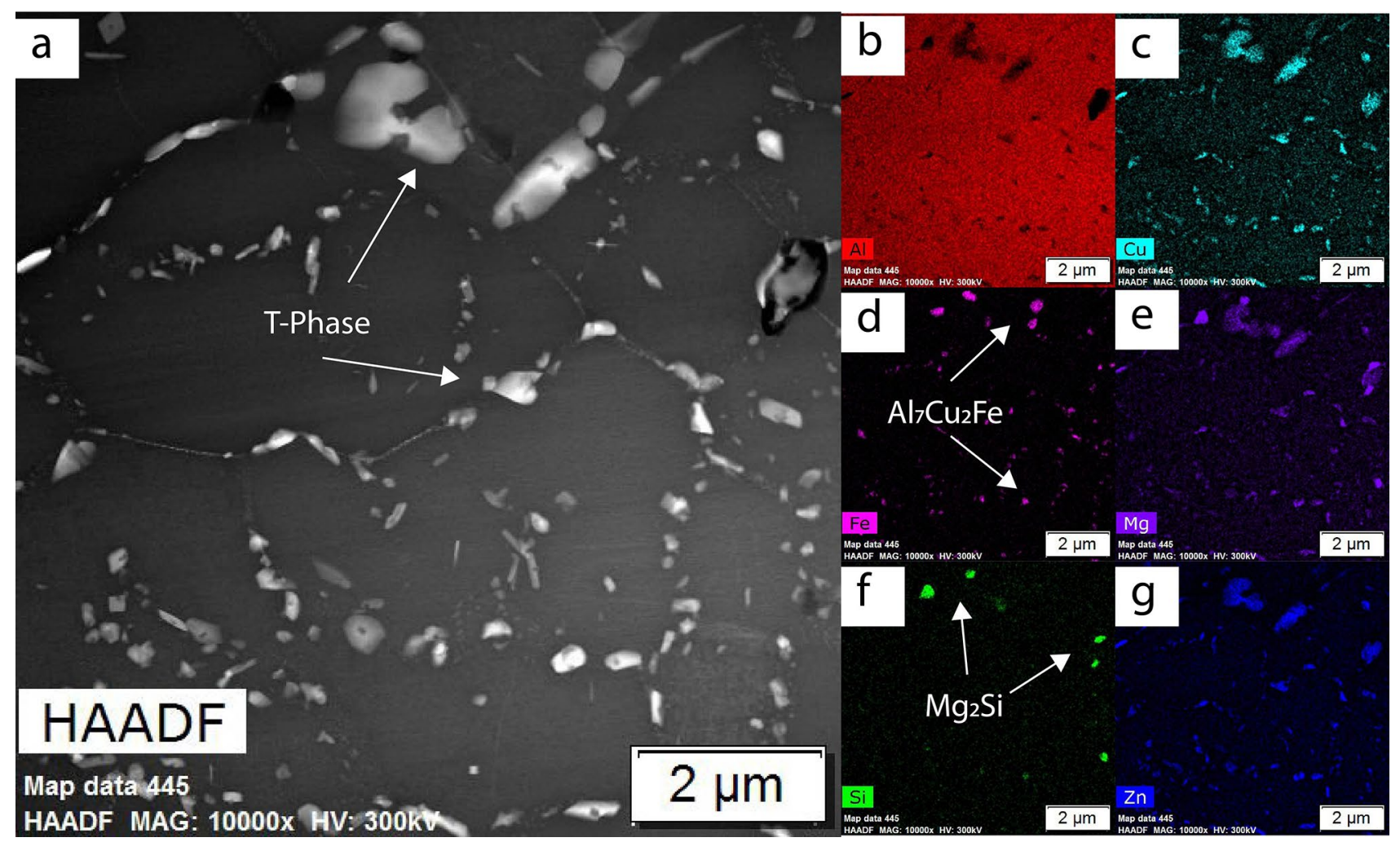

Fig. 8 TEM micrograph and EDS maps for the 60 min at $480^{\circ} \mathrm{C}$ condition. (a) HAADF, (b) $\mathrm{Al}$, (c) $\mathrm{Cu},(\mathbf{d}) \mathrm{Fe},(\mathbf{e}) \mathrm{Mg}$, (f) $\mathrm{Si}$, and (g) $\mathrm{Zn}$

Table 2 EDS point quantification for secondary phases in TEM samples (in wt.\%)

\begin{tabular}{|c|c|c|c|c|c|c|c|c|}
\hline \multirow{2}{*}{$\begin{array}{l}\text { Suggested } \\
\text { phase }\end{array}$} & \multicolumn{4}{|c|}{ As-atomized } & \multicolumn{4}{|l|}{$480{ }^{\circ} \mathrm{C}$} \\
\hline & Matrix & T-phase & $\mathrm{Al}_{7} \mathrm{Cu}_{2} \mathrm{Fe}$ & $\mathrm{Mg}_{2} \mathrm{Si}$ & Matrix, \% & T-phase & $\mathrm{Al}_{7} \mathrm{Cu}_{2} \mathrm{Fe}$ & $\mathrm{Mg}_{2} \mathrm{Si}$ \\
\hline $\mathrm{Al}$ & $90.45 \%$ & $33.80 \%$ & $62.00 \%$ & $14.00 \%$ & 86.82 & $19.33 \%$ & $65.40 \%$ & $3.00 \%$ \\
\hline $\mathrm{Cr}$ & $0.10 \%$ & $\ldots$ & $\ldots$ & $\ldots$ & 0.07 & $\ldots$ & $\ldots$ & $\ldots$ \\
\hline $\mathrm{Fe}$ & $0.10 \%$ & $\ldots$ & $14.50 \%$ & $\ldots$ & 0.08 & $\ldots$ & $10.80 \%$ & $\ldots$ \\
\hline $\mathrm{Mg}$ & $1.63 \%$ & $22.00 \%$ & $1.00 \%$ & $54.00 \%$ & 5.37 & $26.00 \%$ & $1.00 \%$ & $64.00 \%$ \\
\hline $\mathrm{Si}$ & $\ldots$ & $\ldots$ & $\ldots$ & $26.00 \%$ & 0.01 & $\ldots$ & $\ldots$ & $33.00 \%$ \\
\hline $\mathrm{Ti}$ & $0.02 \%$ & $\cdots$ & $\cdots$ & $\ldots$ & 0.02 & $\ldots$ & $\ldots$ & $\ldots$ \\
\hline $\mathrm{Zn}$ & $6.32 \%$ & $23.00 \%$ & $3.00 \%$ & $1.00 \%$ & 6.29 & $37.33 \%$ & $\cdots$ & $\cdots$ \\
\hline $\mathrm{Cu}$ & $1.34 \%$ & $21.20 \%$ & $19.50 \%$ & $4.00 \%$ & 1.33 & $18.00 \%$ & $22.40 \%$ & $1.00 \%$ \\
\hline Mn & $0.04 \%$ & $\ldots$ & $\ldots$ & $\ldots$ & 0.02 & $\ldots$ & $\ldots$ & $\ldots$ \\
\hline
\end{tabular}

the $465^{\circ} \mathrm{C}$ treatment has precipitates both at the boundaries and in the bulk of the grains, whereas the $480{ }^{\circ} \mathrm{C}$ only has precipitates at the boundaries. Diffusion and nucleation energy are both driving forces in determining both the type and location of precipitates that form. Because the grains are so small in these gas-atomized powders and there is such a small diffusion distance to the substructure boundaries from the center of the grains, the driving force for precipitation on the boundaries is easily achievable; thus, precipitation will occur first and most frequently on the boundaries. However, it is possible for the boundaries to become saturated, forcing precipitation to occur within the bulk of the matrix phase.
This is presumed to be the case in the $465{ }^{\circ} \mathrm{C}$ treatment. The boundaries are saturated with T-phase, which is in the process of dissolving, and with $\mathrm{Al}_{7} \mathrm{Cu}_{2} \mathrm{Fe}$, so the $\mathrm{S}$-phase can only precipitate in the bulk matrix as $\mathrm{Al}_{7} \mathrm{Cu}_{2} \mathrm{Fe}$ is more stable at this temperature. This can be seen in both the SEM and TEM micrographs. In order to prove the precipitation sequence, additional SEM or TEM studies should be performed of heat treatments leading up to $465{ }^{\circ} \mathrm{C}$. Ideally, in situ hot-stage STEM studies could be performed on a grain boundary, similar to the work of Vijayan et al. [18], which would enable direct observation of precipitation and dissolution. 
Table 3 Predicted secondary phase compositions (in wt.\%)

\begin{tabular}{|c|c|c|c|c|c|c|c|c|}
\hline \multirow[t]{2}{*}{ Phase } & \multicolumn{8}{|c|}{ Scheil calculations } \\
\hline & AL13FE4 & $\mathrm{A} 145 \mathrm{~V} 7$ & AL7CU2FE & FCC_A1 matrix & MG2SI_C1 & S-phase & T-phase & V-phase \\
\hline $\mathrm{Al}$ & $60.7 \%$ & $76.9 \%$ & $50.8 \%$ & $85.3 \%$ & & $37.6 \%$ & $22.2 \%$ & $23.7 \%$ \\
\hline $\mathrm{Cr}$ & $\cdots$ & $23.1 \%$ & $\cdots$ & $\cdots$ & $\cdots$ & $\cdots$ & $\cdots$ & $\cdots$ \\
\hline $\mathrm{Fe}$ & $34.0 \%$ & $\ldots$ & $15.0 \%$ & $\ldots$ & $\ldots$ & $\ldots$ & $\ldots$ & $\ldots$ \\
\hline $\mathrm{Mg}$ & $\ldots$ & $\ldots$ & $\ldots$ & $2.1 \%$ & $63.4 \%$ & $17.1 \%$ & $20.0 \%$ & $8.5 \%$ \\
\hline $\mathrm{Si}$ & $\ldots$ & $\ldots$ & $\ldots$ & $\ldots$ & $36.6 \%$ & $0.5 \%$ & $\ldots$ & $\ldots$ \\
\hline $\mathrm{Ti}$ & $\ldots$ & $\ldots$ & $\cdots$ & $\ldots$ & $\ldots$ & $\ldots$ & $\cdots$ & $\cdots$ \\
\hline $\mathrm{Zn}$ & $0.1 \%$ & $\ldots$ & $\ldots$ & $11.1 \%$ & $\ldots$ & $\ldots$ & $44.0 \%$ & $25.9 \%$ \\
\hline $\mathrm{Cu}$ & $\cdots$ & $\ldots$ & $34.2 \%$ & $1.6 \%$ & $\ldots$ & $44.8 \%$ & $13.8 \%$ & $41.9 \%$ \\
\hline $\mathrm{Mn}$ & $5.2 \%$ & $\ldots$ & $\ldots$ & $\ldots$ & $\ldots$ & $\ldots$ & $\ldots$ & $\ldots$ \\
\hline \multirow[t]{2}{*}{ Phase } & \multicolumn{4}{|c|}{$465^{\circ} \mathrm{C}$ equilibrium calculations } & \multicolumn{4}{|c|}{$480{ }^{\circ} \mathrm{C}$ equilibrium calculations } \\
\hline & AL45V7 & AL7CU2FE & FCC_A1 matrix & MG2SI_C1 & AL45V7 & AL7CU2FE & FCC_A1 matrix & MG2SI_C1 \\
\hline $\mathrm{Al}$ & $76.9 \%$ & $50.8 \%$ & $90.5 \%$ & $\ldots$ & $76.9 \%$ & $50.8 \%$ & $90.4 \%$ & \\
\hline $\mathrm{Cr}$ & $23.1 \%$ & $\ldots$ & $\ldots$ & $\ldots$ & $23.1 \%$ & $\ldots$ & $\cdots$ & \\
\hline $\mathrm{Fe}$ & $\cdots$ & $15.0 \%$ & & $\cdots$ & $\ldots$ & $15.0 \%$ & $\cdots$ & $\cdots$ \\
\hline $\mathrm{Mg}$ & $\cdots$ & $\ldots$ & $2.3 \%$ & $63.4 \%$ & $\ldots$ & $\cdots$ & $2.3 \%$ & $63.4 \%$ \\
\hline $\mathrm{Si}$ & $\cdots$ & $\ldots$ & $\cdots$ & $36.6 \%$ & $\ldots$ & $\cdots$ & $\cdots$ & $36.6 \%$ \\
\hline $\mathrm{Ti}$ & $\cdots$ & $\ldots$ & $\cdots$ & $\ldots$ & $\ldots$ & $\cdots$ & $\cdots$ & $\cdots$ \\
\hline $\mathrm{Zn}$ & $\ldots$ & $\ldots$ & $5.8 \%$ & $\ldots$ & $\ldots$ & $\ldots$ & $5.8 \%$ & $\ldots$ \\
\hline $\mathrm{Cu}$ & $\ldots$ & $34.2 \%$ & $1.2 \%$ & $\ldots$ & $\ldots$ & $34.2 \%$ & $1 \%$ & $\ldots$ \\
\hline $\mathrm{Mn}$ & $\ldots$ & $\ldots$ & $\ldots$ & $\ldots$ & $\ldots$ & $\ldots$ & $\ldots$ & $\ldots$ \\
\hline
\end{tabular}

Given the increase in understanding of the phases present in each condition from study in TEM, it is beneficial to revisit Fig. 4 to further understand the trends found in the SEM analysis. Recall the increasing trend in the lightcontrasting phases in the $480{ }^{\circ} \mathrm{C}$ treatments at $60 \mathrm{~min}$; in TEM, two different light-contrasting phases were identified at the boundaries: $\mathrm{Al}_{7} \mathrm{Cu}_{2} \mathrm{Fe}$ and $\mathrm{T}$-phase. As previously stated, the $\mathrm{T}$ phase is in the process of dissolving, so this increase is likely due to the coarsening of the $\mathrm{Al}_{7} \mathrm{Cu}_{2} \mathrm{Fe}$ at a faster rate than the T-phase dissolution. It is expected that after 120 min of treatment, the $\mathrm{T}$ phase would be fully dissolved and the $\mathrm{Al}_{7} \mathrm{Cu}_{2} \mathrm{Fe}$ reached a stable size and fraction, reflected in the plateau in Fig. 4. In comparison, at 60 min of treatment at $465^{\circ} \mathrm{C}$, there is a decreasing trend in the light-contrasting phases in the SEM. This trend is surprising because based on the TEM results, there are three different light-contrasting phases present- $\mathrm{Al}_{7} \mathrm{Cu}_{2} \mathrm{Fe}$ and T-phase at the boundaries and $\mathrm{S}$-phase in the bulk of the grains. Because $\mathrm{S}$-phase is forming, $\mathrm{Al}_{7} \mathrm{Cu}_{2} \mathrm{Fe}$ cannot coarsen. In SEM, S-phase was not detected in the bulk, but this is likely due to the limiting resolution of the SEM; this causes the area fraction to appear lower than expected based on TEM results. With this in mind, it is important to understand the limitations of individual characterization techniques and utilize multiple techniques.

\section{Conclusions}

Extensive electron microscopy in combination with computational thermodynamic and kinetic modeling indicated the presence of $\mathrm{T}$-phase, $\mathrm{Al}_{7} \mathrm{Cu}_{2} \mathrm{Fe}$, and $\mathrm{Mg}_{2} \mathrm{Si}$ in the asatomized condition of this gas-atomized Al 7075 powder. Thermal treatments were performed with the goal of homogenizing the microstructure-dissolving T-phase while avoiding $\mathrm{S}$-phase growth, avoiding $\mathrm{Al}_{7} \mathrm{Cu}_{2} \mathrm{Fe}$ coarsening, and avoiding melting. The temperature of $465{ }^{\circ} \mathrm{C}$ was chosen because the $\mathrm{Al}_{7} \mathrm{Cu}_{2} \mathrm{Fe}$ should coarsen slower at a lower temperature, and this is as low as possible without containing S-phase. The temperature of $480{ }^{\circ} \mathrm{C}$ was chosen because it is the conventional solutionization temperature used for Al 7075. In the samples treated at $465{ }^{\circ} \mathrm{C}, \mathrm{S}$-phase was present, indicating a shift in local equilibrium of the powders as compared to the global composition of the powder batch. In both treatments, 60 min was insufficient to fully dissolve the $\mathrm{T}$ phase. Due to the large interaction volume of the SEM as compared to the size of the precipitates present in these powders, it is not possible to accurately differentiate these phases in the SEM; additional TEM would be necessary to evaluate the time required to fully dissolve the T-phase. 
It is important to understand the benefits, as well as the limitations, of different microscopy techniques and utilize different techniques for different purposes. The SEM is useful for high-throughput measurements and total secondary phase area quantification. However, its lower resolution does not allow for tracking individual secondary phases. The TEM is useful for its high resolution, allowing for better quantification of individual phases. However, the time required for sample preparation limits its feasibility for highthroughput evaluations. Leveraging the strengths of each technique, and coupling both of these microscopy techniques with computational thermodynamic and kinetic modeling, allows for enhanced understanding of the microstructural evolution with decreased time spent on data collection.

Acknowledgements This work was funded by the United States Army Research Laboratory, Grant \#W911NF-15-2-0024. This work was performed in part at the Kostas Advanced Nano-Characterization Facility in Kostas Research Institute at Northeastern University and at the Center for Nanoscale Systems (CNS), a member of the National Nanotechnology Coordinated Infrastructure Network (NNCI), which is supported by the National Science Foundation under NSF Award No. 1541959.

Open Access This article is licensed under a Creative Commons Attribution 4.0 International License, which permits use, sharing, adaptation, distribution and reproduction in any medium or format, as long as you give appropriate credit to the original author(s) and the source, provide a link to the Creative Commons licence, and indicate if changes were made. The images or other third party material in this article are included in the article's Creative Commons licence, unless indicated otherwise in a credit line to the material. If material is not included in the article's Creative Commons licence and your intended use is not permitted by statutory regulation or exceeds the permitted use, you will need to obtain permission directly from the copyright holder. To view a copy of this licence, visit http://creativecommons.org/licenses/by/4.0/.

\section{References}

1. G.E. Totten, D.S. MacKenzie, Handbook of aluminum: vol. 1: physical metallurgy and processes (CRC Press, Boca Raton, 2003), pp. 81-210

2. W.E. Frazier, Metal additive manufacturing: a review. JMEP 23(6), 1917-1928 (2014)

3. M. Rokni, C. Widener, V. Champagne, Microstructural evolution of 6061 aluminum gas-atomized powder and high-pressure coldsprayed deposition. J. Therm. Spray Technol. 23, 514 (2014)

4. K. Tsaknopoulos, C. Walde, V. Champagne, D. Cote, Gas-atomized Al 6061 powder: phase identification and evolution during thermal treatment. JOM (2018). https://doi.org/10.1007/s1183 7-018-3175-7

5. C. Walde, D. Cote, V. Champagne, R. Sisson, Characterizing the effect of thermal processing on feedstock $\mathrm{Al}$ alloy powder for additive manufacturing applications. JMEP (2018). https://doi. org/10.1007/s11665-018-3550-0

6. R. Mehrabian, B.H. Kear, and M. Cohen, Rapid solidification processing. principles and technologies, II, in Proceedings of the International Conference on Rapid Solidification Processing (2nd), March 23-26, 1980, Reston, Virginia USA (1980), pp. 7-8, 22

7. M.E. Fine, Rapidly solidified powder aluminum alloys: a symposium (No. 890) (West Conshohocken, ASTM International, 1986), p. 85

8. W.J. Ullrich, Powder metallurgy in defense technology, in Proceedings of the 1986 P/M in Defense Technology Seminar, David Taylor Naval Ship Research \& Development Center, December 3-4, 1986, Annapolis, Maryland, USA (1986), p. 88

9. G.E. Totten, D.S. MacKenzie, Handbook of aluminum: vol. 1: physical metallurgy and processes (CRC Press, Boca Raton, 2003), pp. 259-304

10. A. Sabard, H.L. de Villiers Lovelock, T. Hussain, Microstructural evolution in solution heat treatment of gas-atomized $\mathrm{Al}$ alloy (7075) powder for cold spray. J. Therm. Spray Technol. 27(1-2), 145-158 (2018)

11. M. Rokni, C. Widener, V. Champagne, G. Crawford, S. Nutt, The effects of heat treatment on $7075 \mathrm{Al}$ cold spray deposits. Surf. Coat. Technol. 310, 278-285 (2017)

12. M. Rokni, C. Widener, O. Ozdemir, G. Crawford, Microstructure and mechanical properties of cold sprayed $6061 \mathrm{Al}$ in As-sprayed and heat treated condition. Surf. Coat. Technol. 309, 641-650 (2017)

13. M. Rokni, C. Widener, G. Crawford, M. West, An investigation into microstructure and mechanical properties of cold sprayed $7075 \mathrm{Al}$ deposition. Mater. Sci. Eng. A 625, 19-27 (2015)

14. A. Sabard, H. de Villiers Lovelock, T. Hussain, Microstructural Evolution in Solution Heat Treatment of Gas-Atomized Al Alloy (7075) Powder for Cold Spray. J. Therm. Spray Technol. 27, 145158 (2017)

15. K.L. Tsaknopoulos, Computational thermodynamic and kinetic modeling and characterization of phase transformations in rapidly solidified aluminum alloy powders (Doctoral dissertation, Worcester Polytechnic Institute, Worcester, USA, 2019)

16. ASTM E1097-12 Standard Guide for Determination of Various Elements by Direct Current Plasma Atomic Emission Spectrometry, ASTM International, West Conshohocken, PA (2012). https ://doi.org/10.1520/E1097-12

17. ASTM B209-10 Standard Specification for Aluminum and Aluminum-Alloy Sheet and Plate, ASTM International, West Conshohocken, PA (2010). https://doi.org/10.1520/B0209-10

18. S. Vijayan, B. Beddard, M. Gleason, H. Leonard, D. Cote, M. Aindow, Studies of thermally activated processes in gas-atomized Al alloy powders: in situ STEM heating experiments on FIB-cut cross sections. J. Mater. Sci. 54, 9921-9932 (2019)

Publisher's Note Springer Nature remains neutral with regard to jurisdictional claims in published maps and institutional affiliations. 